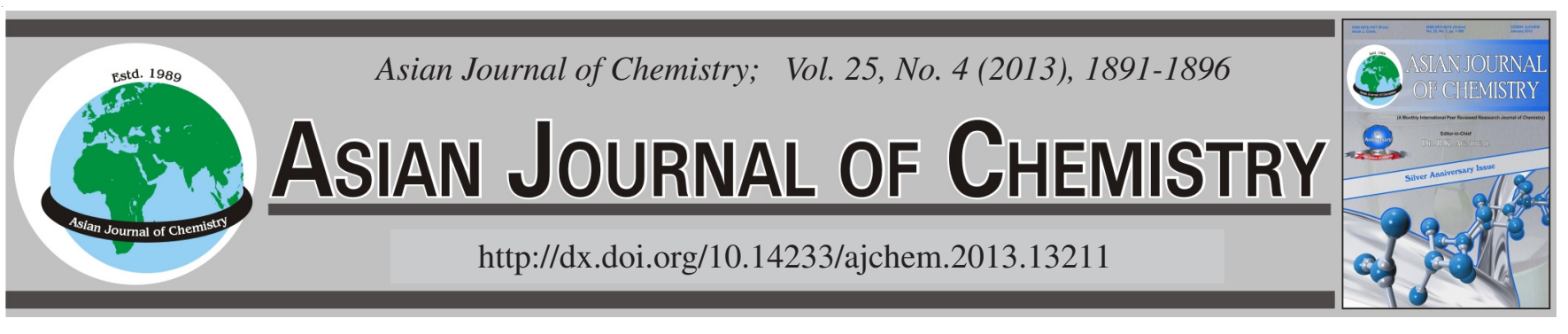

\title{
Simulation Study on Natural Attenuation of Nitrobenzene in Natural Water
}

\author{
BaOlin Liu ${ }^{1,2}$, XiUyi Hua ${ }^{1}$, Deming Dong ${ }^{1, *}$ and Ming Li ${ }^{1}$
}

${ }^{1}$ Key Lab of Groundwater Resources and Environment of Ministry of Education, College of Environment and Resources, Jilin University, Changchun 130012, Jilin Province, P.R. China

${ }^{2}$ College of Chemistry, Changchun Normal University, Changchun 130032, Jilin Province P.R. China

*Corresponding author: Fax: +86 431 84727678; Tel: +86 431 86168099; E-mail: dmdong@jlu.edu.cn

This work reports the different aspects of nitrobenzene attenuated in natural water environments under the typical experimental conditions. We usd computer to fit the total reaction rate constants and that in all the aspects and compared between the box model fitting results and experimental results. We analyzed the major fate of nitrobenzene in natural water environments. Studies have shown that the major fate of nitrobenzene in simulated natural water was adsorption, in contrast to adsorption, photodegradation predominanted in the process, followed by evaporation and desorption and compared to other attenuation, the biodegradation process was relatively slow and did not play a leading role.

Key Words: Nitrobenzene, Volatilization, Biodegradation, Photodegradation, Adsorption/desorption.

ᄂ - - - - - - - - - - - - - - - - - - - - - - - - - - - - - - - -

\section{INTRODUCTION}

In contemporary society, organic pollution has become a global problem. The major migration and transformation processes of organic pollutants in rivers are volatilization, photodegradation, biodegradation, bioamplification and the interaction between organic pollutants and sediments in rivers, etc. The migration and transformation processes of organic pollutants in water environments can be achieved by a simulated method ${ }^{1-4}$. Neely's simulation study researched the migration and transformation processes of the PCBs in the Michigan Lake ; Bernadette et al. ${ }^{6}$ studied the distribution and fate of chlorophenol in the St. lawrence river ${ }^{6} ;$ Ye et al. ${ }^{7}$ researched the water quality model and influencing factors of the Lijiang river ${ }^{7}$.

Nitrobenzene is light yellow oil liquid with bitter almond flavor. Nitrobenzene is insoluble in water; soluble in ethanol, ether, benzene and oil. The absorption rates of nitrobenzene contaminated skin is $2 \mathrm{mg} / \mathrm{cm}^{2} \mathrm{~h}$, while the steam which can be absorbed by the skin and the respiratory tract and the total retention rate in the body rise to $80 \%$. The major conversion of nitrobenzene are $p$-aminophenol, little $m$-nitrophenol and $p$-nitrophenol and $o$ - and amino phenol. The intermediate materials of biotransformation are more toxic than its parent population.

The major migration and transformation processes of nitrobenzene in rivers are controled by a variety of physical, chemical and biological processes. Therefore, it is indispensable to predict the migration and transformation processes of organic pollutants in rivers with applied physical, chemical and biological models. Moreover, these predictions have important meanings on human health and the degree of environmental hazards. It can also reduce the costs of monitor and save manual labour and material resources. So far, there are many domestic and foreign scholars have brought a number of practical models about the migration and transformation of organic pollutants in rivers ${ }^{8,9}$.

This paper is based on previous work and applies the box model of compounds in the river with specific test to predict the natural attenuation of nitrobenzene in natural waters. It has theoretical and practical significance.

\section{EXPERIMENTAL}

Sample collection and pretreatment: The sampling position in this paper is at east of the Longtan Bridge where is $100 \mathrm{~m}$ away from Jilin section, the Songhua River. Water samples were collected in September 2006. Without stirring the sediments in bottom, we drew water into polyethylene buckets. After that these samples were shipped back to the laboratory and used the filter membrane(aperture: $0.45 \mu \mathrm{m}$ ) to filter suspended particulate in water under vacuum highpressure. Then we discarded particulate and saved the polyethylene buckets of water samples into fridge under $5^{\circ} \mathrm{C}$. Sediment samples were in the flat or still waters, so we collected 
them under water where was $2 \mathrm{~m}$ and $1 \mathrm{~m}$ away from offshore with a plastic shovel (the sampling depth was $5 \mathrm{~cm}$ ), then drained and packed them in plastic bags; transported back to the laboratory. Under the room temperature, the samples were air dried and cleared by the impurities of gravel and debris of plants. Putting the samples which grinded by a mortar to a 200 sievemesh. After that we put the samples into black plastic bottles and labelled them as backups.

Experimental conditions: Condition 1: experimental temperature: $25^{\circ} \mathrm{C}$; $\mathrm{pH}$ value: 7.44 ; concentration of nitrobenzene: $0.2 \mathrm{mg} / \mathrm{L}$. Condition 2: experimental temperature: $10{ }^{\circ} \mathrm{C}$; $\mathrm{pH}$ value: 8.44 ; concentration of nitrobenzene: $1 \mathrm{mg} / \mathrm{L}$.

Determination of gas chromatography: Chromatographic column: EC-20 quartz capillary gas chromatography column; input temperature: $240^{\circ} \mathrm{C}$; detector temperature: 260 ${ }^{\circ} \mathrm{C}$; column temperature: $100{ }^{\circ} \mathrm{C}$; carrier gas: high-purity $\mathrm{N}_{2}$, sample size: $1 \mu \mathrm{L}$.

\section{Experimental process of nitrobenzene attenuation}

Evaporation process: The initial concentration of nitrobenzene was $200 \mathrm{mg} / \mathrm{L}$, adding sodium azide to prevent biodegradate. To set $\mathrm{pH}$, open bottles, adjust to certain speed, take a sample every 2 days and measure the concentration of nitrobenzene.

Biodegradation: Prepare some $250 \mathrm{~mL}$ Erlenmeyer flasks which have sterilized, then add $150 \mathrm{~mL}$ solution of nitrobenzene which has regulated with river water. Using two layers of gauzes which wrapped with absorbent cotton to block the bottles, then placing them in the homoeothermic incubator. Later, testing the content of nitrobenzene every 2 days when it changed with time ${ }^{10}$. The experiments of biodegradation used sediments which contaminated by nitrobenzene to cultivate them in the homoeothermic incubator (in this process, avoiding light). The concentration of nitrobenzene changed with time.

Photodegradation: To compound the certain concentration of nitrobenzene and degradate them under $290 \mathrm{~nm}$ light source of xenon (light intensity: 45700 Lux). Then we stirred them with magnetic and fixed the temperature. The concentration of nitrobenzene changed with time.

Adsorption kinetics: The initial concentration of nitrobenzene: $200 \mathrm{mg} / \mathrm{L}$; the ratio of mud and water: 1:10; adsorption time: $8-12 \mathrm{~h}$; the background solution: $1 \mathrm{mmol} / \mathrm{L} \mathrm{CaCl}_{2}$, $0.1 \mathrm{mmol} / \mathrm{L} \mathrm{MgCl}_{2}, 0.5 \mathrm{mmol} / \mathrm{L} \mathrm{Na}_{2} \mathrm{~B}_{4} \mathrm{O}_{7} \cdot 10 \mathrm{H}_{2} \mathrm{O}$ (the ionic strength was closed to the river, so except the experimental effects of ionic strength). The concentration of nitrobenzene that changed with time.

Desorption kinetics: The quality of contaminated sediments: $60 \mathrm{~g}$; the ratio of mud and water: 1:10. Then adding $\mathrm{NaN}_{3}$ (its concentration was $200 \mu \mathrm{g} / \mathrm{L} / \mathrm{L}$ ), desorption time: 8-12 h. The concentration of nitrobenzene changed with time.

Simulation test of natural attenuation of nitrobenzene in water environments: To prepare some $250 \mathrm{~mL}$ Erlenmeyer flasks which have sterilized, then add $150 \mathrm{~mL}$ solution of nitrobenzene which has regulated the $\mathrm{pH}$ with river water. Opening the bottles and placing them in the homoeothermic incubator. We mediated temperature and open the light source of xenon, while began to oscillate. Testing the content of nitrobenzene at regular intervals when it changed with time.

\section{RESULTS AND DISCUSSION}

Volatilization of nitrobenzene in water environments: The evaporation rates of nitrobenzene in river environments that we worked out through the simulation. The results shown in Fig. 1. Based on relevant literature, Yuan-Hui Zhao and other people $\mathrm{e}^{11-13}$ found that the volatilization process of nitrobenzene fitted in first-order kinetic model by computer simulation. The equation was:
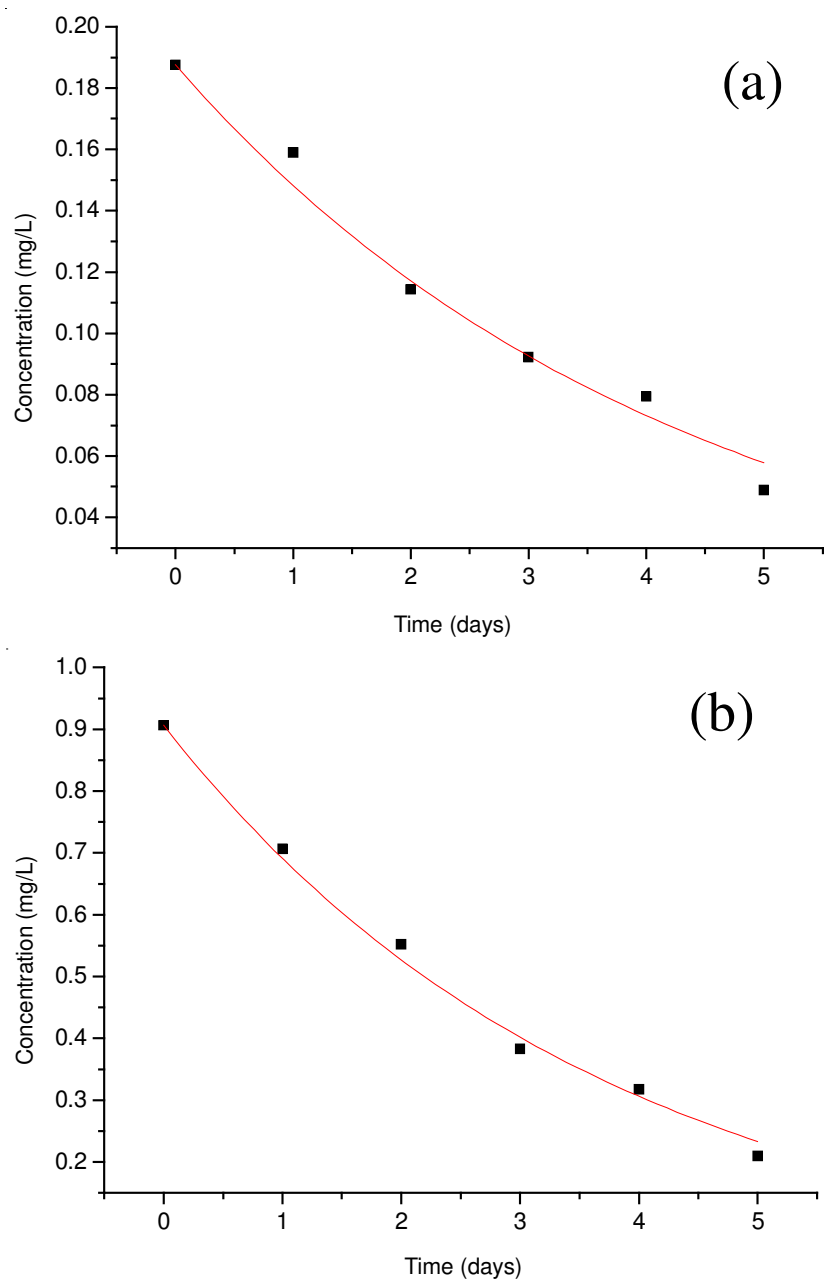

Fig. 1. Volatilization process of nitrobenzene in water environments (a) under condition 1 , the volatilization process of nitrobenzene in water environments (b) under condition 2, the volatilization process of nitrobenzene in water environments

$$
\mathrm{C}_{\mathrm{w}}=\mathrm{C}_{\mathrm{w}}{ }^{0} \mathrm{e}^{-\mathrm{K}}{ }_{\mathrm{v}} \mathrm{t}
$$

In this equation, $\mathrm{C}_{\mathrm{w}}$ : the concentration of nitrobenzene in aqueous solution; $\mathrm{C}_{\mathrm{w}}{ }^{0}$ : the initial concentration of nitrobenzene in aqueous solution; $\mathrm{K}_{\mathrm{v}}$ : the evaporation rate constants $(1 / \mathrm{h})$; $\mathrm{t}$ : time. According to the experimental data of first-order kinetic model, calculating the evaporation rate constant.

Biodegradation of nitrobenzene in water environments: The biodegradation processes of nitrobenzene in water environments under conditions 1,2 and aerobiotic. The results shown in Fig. 2. Based on the experimental results, the biodegradation process of nitrobenzene in aqueous solution fitted first-order kinetic model. The equation was:

$$
\mathrm{C}_{\mathrm{w}}=\mathrm{C}_{\mathrm{w}}{ }^{0} \mathrm{e}^{-\mathrm{K}}{ }_{\mathrm{bw}} \mathrm{t}
$$



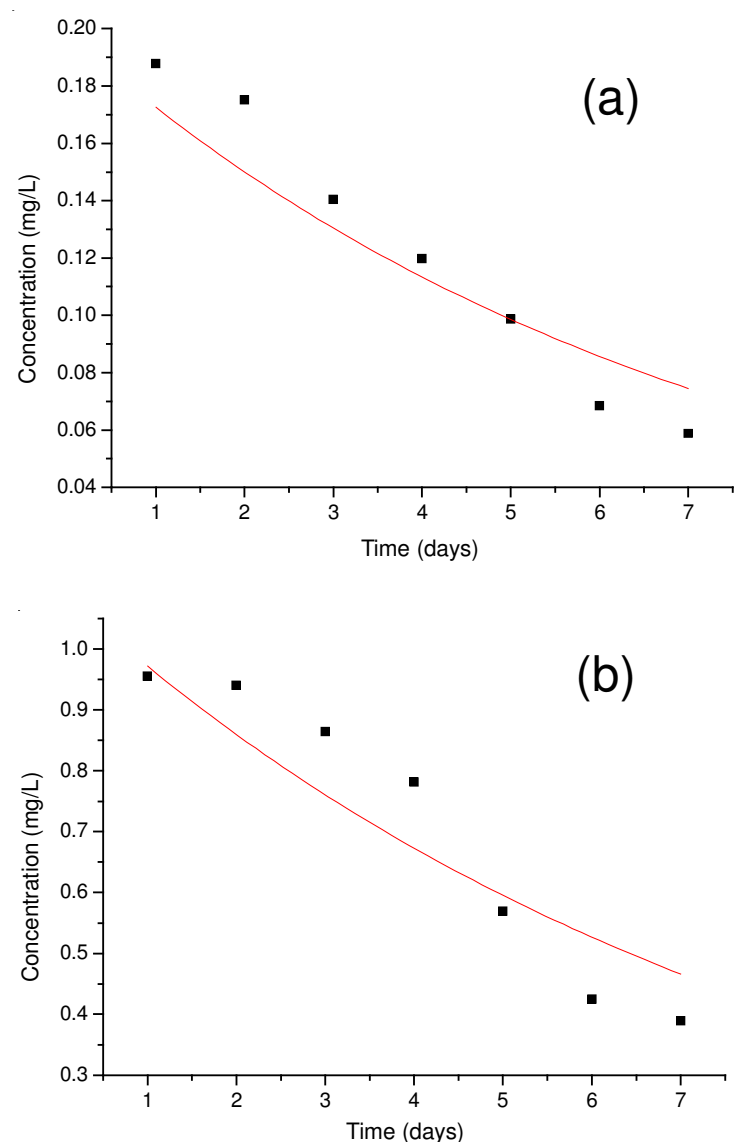

Fig. 2. Biodegradation process of nitrobenzene in water environments (a) under condition 1, the biodegradation process of nitrobenzene in water environments (b) under condition 2, the biodegradation process of nitrobenzene in water environments

In this equation, $\mathrm{C}_{\mathrm{w}}, \mathrm{C}_{\mathrm{w}}{ }^{0}$, $\mathrm{t}$ are the same with the rates of volatilization process; $\mathrm{K}_{\mathrm{bw}}$ : the biodegradation rate constant of nitrobenzene $(1 / \mathrm{h})$. According to the experimental data of first-order kinetic model, calculating the biodegradation rate constant.

Biodegradation of nitrobenzene in sediments: The biodegradation rates of nitrobenzene in pre-contaminated sediments were under condition 1 and condition 2 . In order to simulate the actual degradation in rivers, the experiments were carried out under aerobic conditions. The results shown in Fig. 3. Based on the experimental results, the degradation process fitted first-order kinetic model. The equation was:

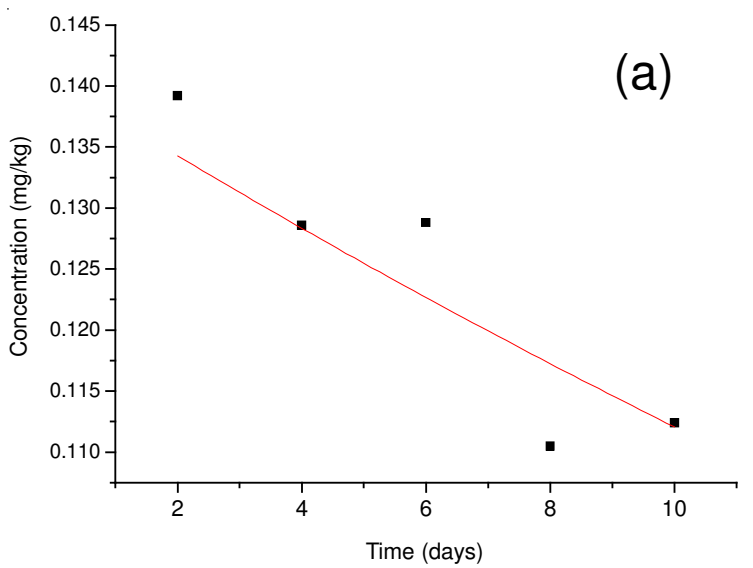

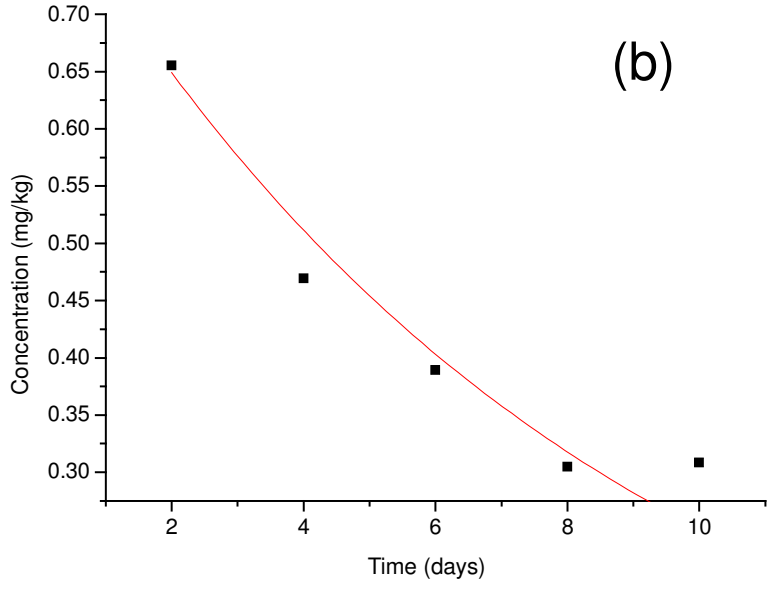

Fig. 3. Biodegradation of nitrobenzene in sediments which polluted by nitrobenzene (a) under condition 1, the biodegradation of nitrobenzene in sediments (b) under condition 2 , the biodegradation of nitrobenzene in sediments

$$
\mathrm{C}_{\mathrm{s}}=\mathrm{C}_{\mathrm{s}}{ }^{0} \mathrm{e}^{-\mathrm{K}}{ }_{\text {bs }} \mathrm{t}
$$

In this equation, $\mathrm{C}_{\mathrm{s}}$ : the concentration of nitrobenzene in sediments $(\mathrm{mg} / \mathrm{kg}) ; \mathrm{C}_{\mathrm{s}}{ }^{0}$ : the initial concentration of nitrobenzene in sediments; $\mathrm{K}_{\mathrm{s}}$ : the biodegradation rate constant of nitrobenzene in sediments $(1 / \mathrm{h})$; $\mathrm{t}$ : time.

Under conditions 1 and 2, the degradation was fitted firstorder kinetic model, then we calculated the degradation rate constant of nitrobenzene.

Photodegradation of nitrobenzene in water environments: The photodegradation of nitrobenzene in water environments under condition 1 and condition 2. The results shown in Fig. 4. Based on the experimental results, the degradation process fitted first-order kinetic model. The equation was:

$$
\mathrm{C}_{\mathrm{w}}=\mathrm{C}_{\mathrm{w}}{ }^{0} \mathrm{e}^{-\mathrm{K}_{\mathrm{s}} \mathrm{t}}
$$

In this equation, $\mathrm{C}_{\mathrm{w}}, \mathrm{C}_{\mathrm{w}}{ }^{0}, \mathrm{t}$ are the same with the rates of volatilization process; $\mathrm{K}_{\mathrm{s}}$ : the photodegradation rate constant of nitrobenzene $(1 / \mathrm{h})$. According to the experimental data of first-order kinetic model, calculating the $\mathrm{K}_{\mathrm{s}}$.

Adsorption kinetic feature of nitrobenzene: Under condition 1 and condition 2, we carried out the experiment of adsorption kinetics with the samples which were collected from the $100 \mathrm{~m}$ downstream to the Longtan bridge. The results shown in Fig. 5.

During the adsorption process of organics, the adsorption/ desorption occured simultaneously. So two-compartment mode could describe both reversible processes at the same time. We used the modified two-compartment model to fit the diversification of solutions' concentration and worked out the rate constant of adsorption/desorption. According to the two-compartment model, we ignored the loss of volatilization during the experiment and considered the mud and water that were mixed perfectly. On the basis of the experimental results, the adsorption / desorption of nitrobenzene were fitted first-order kinetic model. The equation was:

$$
\mathrm{C}_{\mathrm{w}}=\frac{\mathrm{C}_{\mathrm{w}}^{0}\left[\mathrm{~K}_{\mathrm{d}}+\mathrm{K}_{\mathrm{a}} \mathrm{SWe}^{-\left(\mathrm{K}_{\mathrm{d}}+\mathrm{K}_{\mathrm{a}} \mathrm{SW}\right)} \mathrm{t}\right]}{\left(\mathrm{K}_{\mathrm{d}}+\mathrm{K}_{\mathrm{a}} \mathrm{SW}\right)}
$$

In this equation, $\mathrm{C}_{\mathrm{w}}$ : the concentration of nitrobenzene in water $(\mathrm{mg} / \mathrm{L}) ; \mathrm{C}_{\mathrm{w}}{ }^{0}$ : the initial concentration of nitrobenzene; 

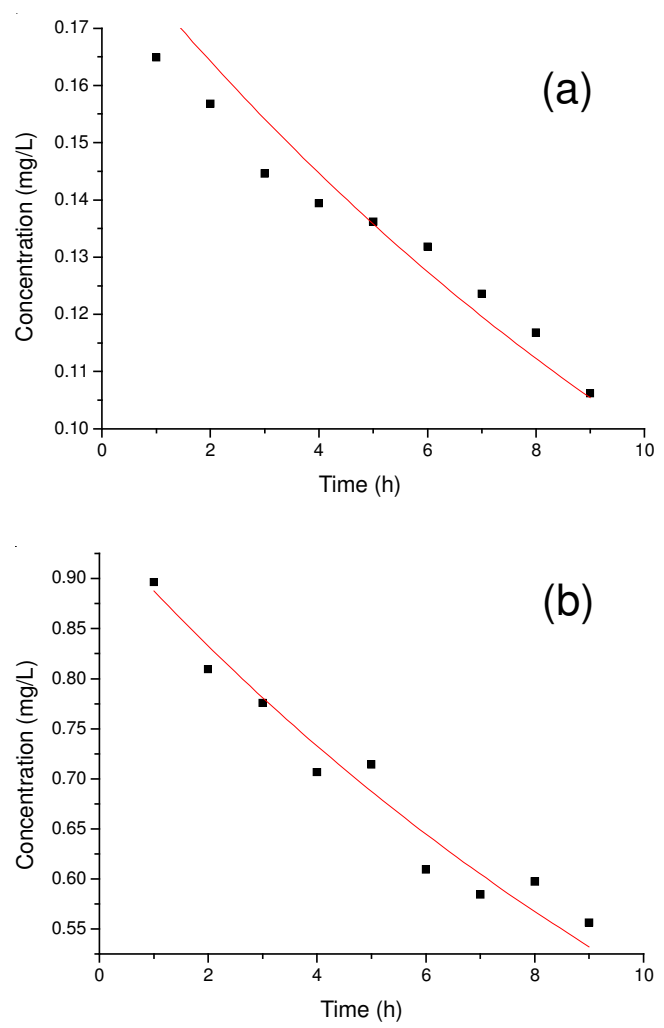

Fig. 4. Photodegradation process of nitrobenzene in water environments (a) under condition 1, the photodegradation process of nitrobenzene in water environments (b) under condition 2, the photodegradation process of nitrobenzene in water environments
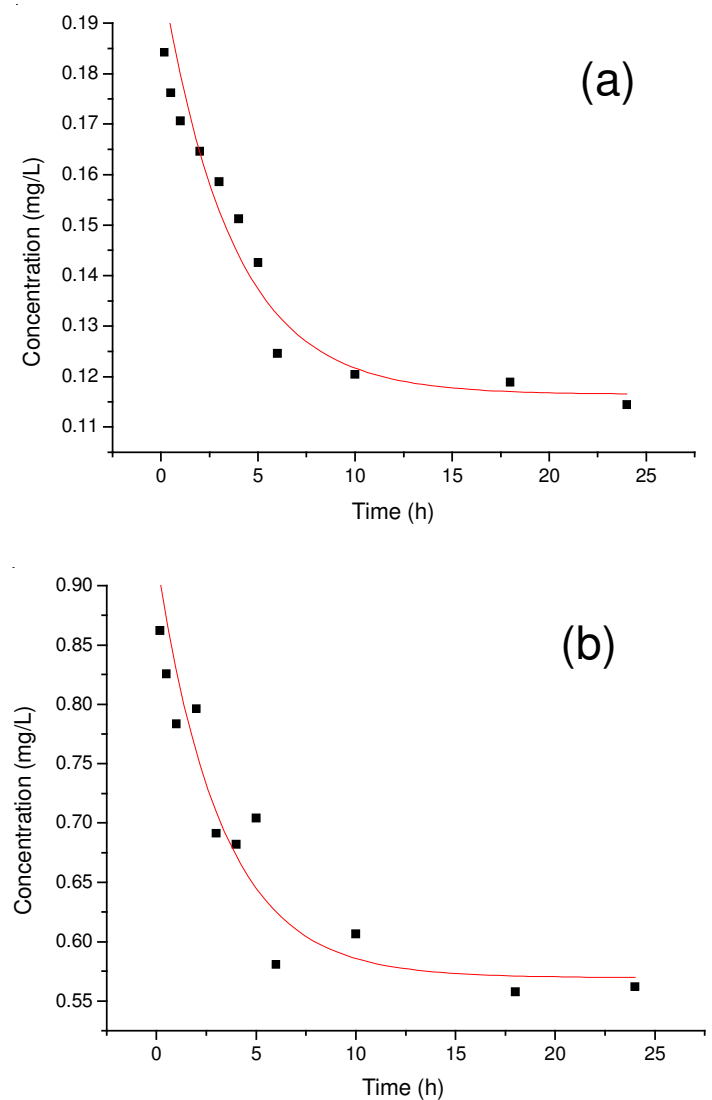

Fig. 5. Nitrobenzene adsorption kinetic process of sediments (a) under condition 1, the nitrobenzene adsorption kinetic process of sediments (b) under condition 2 , the nitrobenzene adsorption kinetic process of sediments
$\mathrm{K}_{\mathrm{d}}$ : the evolution rate constant of nitrobenzene in sediments $(1 / \mathrm{h}), \mathrm{K}_{\mathrm{a}}$ : the adsorption rate constant of nitrobenzene in sediments $(\mathrm{L} /(\mathrm{kg} \mathrm{h})), \mathrm{SW}$ : the ratio of mud and water $(\mathrm{kg} / \mathrm{L}$, in this paper is 0.1$)$; $\mathrm{t}$ : time (h). Using the data of the twocompartment model (Figs. 3-5) to fit the rate constant of adsorption.

It can be seen from the figures that under the two conditions, the adsorption processes of nitrobenzene were fierce within $6 \mathrm{~h}$, but after $6 \mathrm{~h}$ the concentration of nitrobenzene were stable. It indicated that the process of adsorption has been completed for $6 \mathrm{~h}$. Under the temperature and adsorption conditions, when the adsorption got balanced, $c a$. 36$40 \%$ of nitrobenzene were adsorbed.

Desorption kinetic feature of nitrobenzene: Under condition 1 and condition 2, we carried out the experiment of adsorption kinetics with the samples which were collected from the $100 \mathrm{~m}$ downstream to Longtan bridge. The results shown in Fig. 6. According to two-compartment model, we figured out:
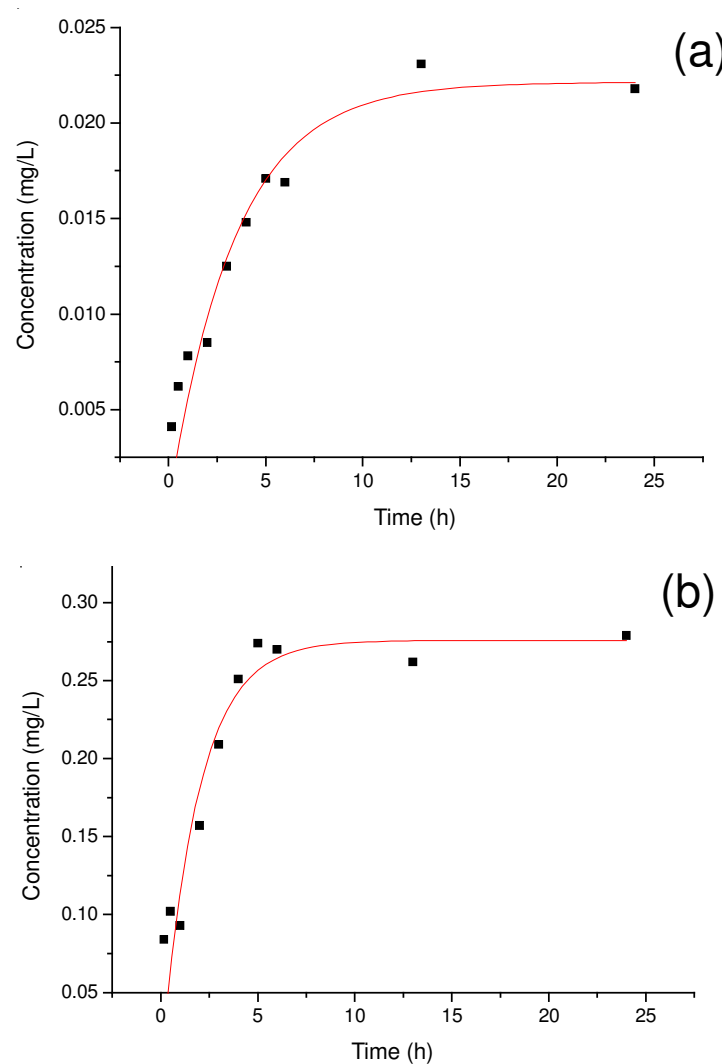

Fig. 6. Desorption kinetic process of nitrobenzene in aqueous solution which contaminated by nitrobenzene (a) under condition 1 , the desorption kinetic process of nitrobenzene in sediments (b) under condition 2, the desorption kinetic process of nitrobenzene in sediments

$$
C_{w}=\frac{K_{d} S W C_{s}^{0}\left[1-e^{-\left(K_{d}+K_{a} S W\right)} t\right]}{\left(K_{d}+K_{a} S W\right)}
$$

In this equation, $\mathrm{C}_{\mathrm{w}}$ : the concentration of nitrobenzene in water $(\mathrm{mg} / \mathrm{L}) ; \mathrm{C}_{\mathrm{w}}{ }^{0}$ : the initial concentration of nitrobenzene; $\mathrm{K}_{\mathrm{d}}$ : the evolution rate constant of nitrobenzene in sediments $(1 / h) ; K_{a}$ : the adsorption rate constant of nitrobenzene in sediments $(\mathrm{L} /(\mathrm{kg} \mathrm{h})) ; \mathrm{SW}$ : the ratio of mud and water $(\mathrm{kg} / \mathrm{L}$, 
in this paper is 0.1$)$; $t$ : time $(\mathrm{h})$. Using the data of the twocompartment model (Figs. 3-6) to fit the rate constants of adsorption.

It can be seen from the figure that the sediments which adsorbed the nitrobenzene released obviously and the speed was faster. After $6 \mathrm{~h}$ the main quick-release process has been completed, then into the slow release phase and finally stabilized. It was consistent with the previous work in our laboratory. Under the two conditions, we calculated through mass balance and known the amount of released nitrobenzene was $\mathrm{ca} .70 \%$.

Natural attenuation features of nitrobenzene in water environments: To synthesize every concrete processes of nitrobenzene's natural attenuation in a simulated natural water environment. The results about the integrated attenuation processes of nitrobenzene shown in Fig. 7. We can see from the figure that under the two conditions, the amount of nitrobenzene after $24 \mathrm{~h}$ was $c a$. 15-20\%. In a simulated natural water environment, the natural decay process was very rapid, but according to the previous researches that we known the main fate of nitrobenzene was adsorption. There was a certain amount of degradation and volatilization of nitrobenzene and a amount of biodegradation of nitrobenzene was less than before. The above fitness rate results shown in Table-1.
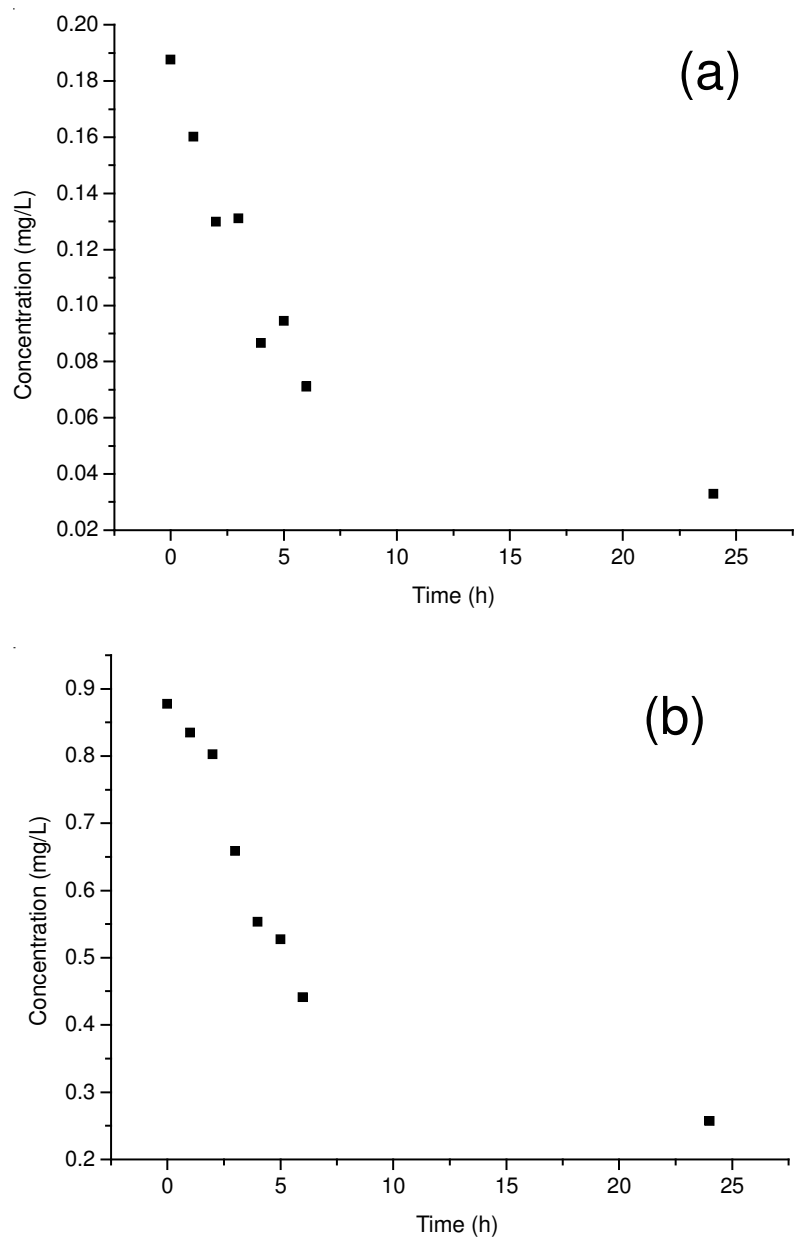

Fig. 7. Integrated attenuation process of nitrobenzene in a simulated natural water environment (a) under condition 1 , the integrated attenuation process of nitrobenzene in a simulated natural water environment (b) under condition 2, the integrated attenuation process of nitrobenzene in a simulated natural water environment
TABLE-1

ATTENUATION FITNESS OF NITROBENZENE IN THE SIMULATED NATURAL WATER ENVIRONMENT UNIT: $1 / \mathrm{h}$

Conditions attenuation processes $\quad$ Condition 1 Condition 2

Volatilization $\mathrm{K}_{\mathrm{v}} \quad 0.0098 \quad 0.01125$

Biodegradation under water $\mathrm{K}_{\mathrm{bw}} \quad 0.0058 \quad 0.0051$

Biodegradation of sediments $\mathrm{K}_{\mathrm{bs}} \quad 0.000942 \quad 0.004958$

Photodegradation $\mathrm{K}_{\mathrm{s}} \quad 0.06334 \quad 0.06393$

Adsorption $\mathrm{K}_{\mathrm{a}} \quad 1.1589 \quad 1.1781$

Resolution $\mathrm{K}_{\mathrm{d}} \quad 0.2232 \quad 0.3903$

Comparisons between actual results and the results of box model: Through the above groups, we can measure the migration and transformation rate constants of organics and estimate the migration and transformation processes of the total organic pollutants. In this model, migration and transformation were fitted the following equations:

$$
\begin{gathered}
\frac{\mathrm{dC}_{\mathrm{w}}}{\mathrm{dt}}=-\left(\mathrm{K}_{\mathrm{v}}+\mathrm{K}_{\mathrm{bw}}+\mathrm{K}_{\mathrm{a}} \mathrm{SW}\right) \mathrm{C}_{\mathrm{w}}+\mathrm{K}_{\mathrm{d}} \mathrm{C}_{\mathrm{s}} \mathrm{SW} \\
\frac{\mathrm{dC}_{\mathrm{s}}}{\mathrm{dt}}=\mathrm{K}_{\mathrm{a}} \mathrm{C}_{\mathrm{w}}-\left(\mathrm{K}_{\mathrm{d}}+\mathrm{K}_{\mathrm{bs}}\right) \mathrm{C}_{\mathrm{s}}
\end{gathered}
$$

In this equation, $\mathrm{K}_{\mathrm{s}}$ : the photolysis rate constant of organics $\left(\mathrm{h}^{-1}\right) ; \mathrm{K}_{\mathrm{v}}$ : the volatilization rate constant of organics $\left(\mathrm{h}^{-1}\right) ; \mathrm{K}_{\mathrm{a}}$ : the adsorption rate constant of organics $\left(\mathrm{L} \mathrm{kg}^{-1} \mathrm{~h}^{-1}\right)$; $\mathrm{K}_{\mathrm{bw}}$ : the microbial degradation rate constant of organic pollutants in water $\left(\mathrm{h}^{-1}\right) ; \mathrm{K}_{\mathrm{bs}}$ : the microbial degradation rate constant of organic pollutants in the sediments $\left(\mathrm{h}^{-1}\right) ; \mathrm{K}_{\mathrm{d}}$ : the desorption rate constant of the organics $\left(\mathrm{h}^{-1}\right) ; \mathrm{C}_{\mathrm{s}}$ : the concentration of organics in the sediments $\left(\mathrm{mg} \mathrm{kg}^{-1}\right) ; \mathrm{C}_{\mathrm{w}}$ : the concentration of organics in aqueous phase $\left(\mathrm{mg} \mathrm{L}^{-1}\right)$; t: time $(\mathrm{h})$; $\mathrm{V}$ : volume of water $(\mathrm{L})$; $\mathrm{SW}$ : the ratio of mud and water $\left(\mathrm{kg} \mathrm{L}^{-1}\right)$.

According to the box model, we worked out the following relationship by integrating the two equations.

$\mathrm{C}_{\mathrm{w}}=\mathrm{C}_{\mathrm{w}}{ }^{0}\left(\mathrm{~K}_{\mathrm{v}}+\mathrm{K}_{\mathrm{bw}}+\mathrm{K}_{\mathrm{s}}+\mathrm{K}_{\mathrm{a}} \mathrm{SW}\right)\left(\mathrm{K}_{\mathrm{d}}+\mathrm{K}_{\mathrm{bs}}\right) \times \exp \left[-\left(\mathrm{K}_{\mathrm{v}}+\mathrm{K}_{\mathrm{bw}}\right.\right.$ $\left.\left.+\mathrm{K}_{\mathrm{s}}+\mathrm{K}_{\mathrm{a}} \mathrm{SW}\right) \times \mathrm{t}\right\} /\left\{\left(\mathrm{K}_{\mathrm{v}}+\mathrm{K}_{\mathrm{bw}}+\mathrm{K}_{\mathrm{s}}+\mathrm{K}_{\mathrm{a}} \mathrm{SW}\right)\left(\mathrm{K}_{\mathrm{d}}+\mathrm{K}_{\mathrm{bs}}\right)-\right.$ $\mathrm{K}_{\mathrm{a}} \mathrm{K}_{\mathrm{d}} \mathrm{SW} \times\left\{1-\exp \left[-\left(\mathrm{K}_{\mathrm{v}}+\mathrm{K}_{\mathrm{bw}}+\mathrm{K}_{\mathrm{s}}+\mathrm{K}_{\mathrm{a}} \mathrm{SW}\right) \times \mathrm{t}\right]\right\} \times\{1-\exp [-$ $\left.\left.\left.\left(\mathrm{K}_{\mathrm{d}}+\mathrm{K}_{\mathrm{bs}}\right) \times \mathrm{t}\right]\right\}\right\}$

Under condition 1 and condition 2, we put all the rate constants into the equation. The comparisons about natural attenuation of nitrobenzene in a simulated natural water environment shown in Fig. 8 and the equation results shown in Table-2.

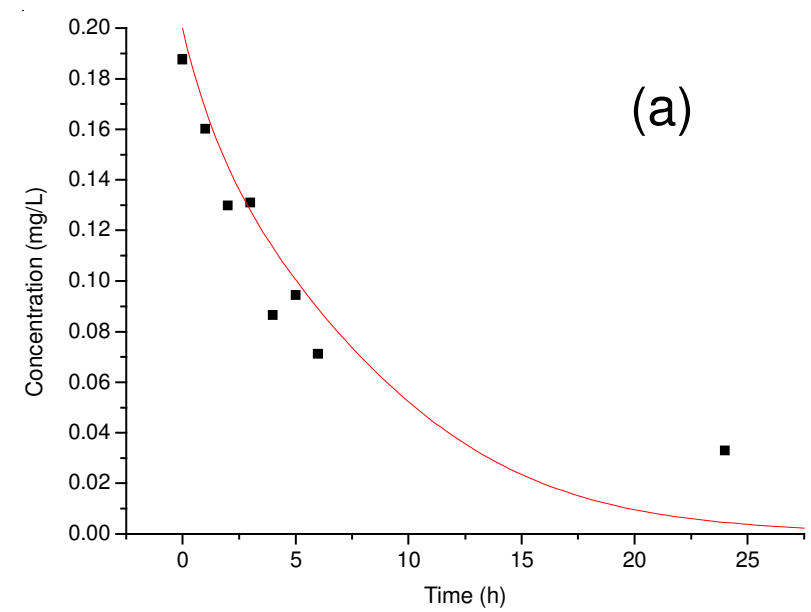




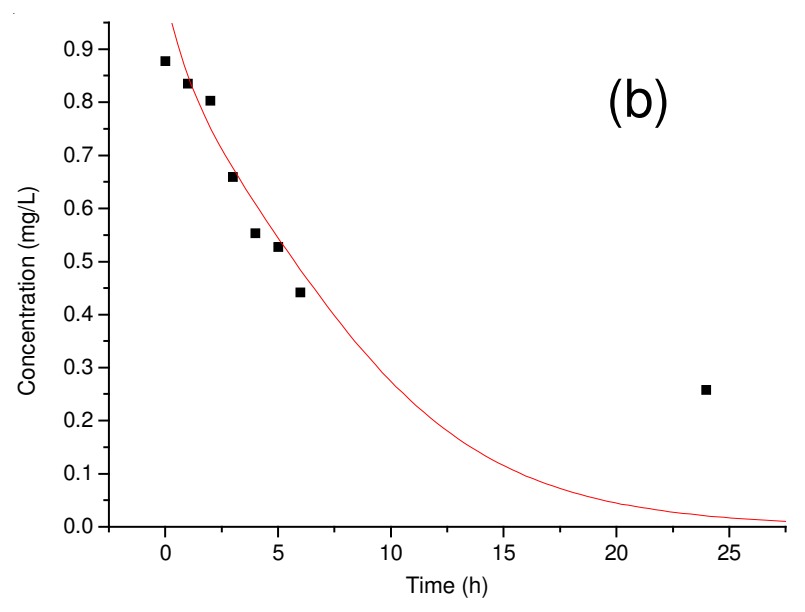

Fig. 8. Control results between fitting curve and test value of nitrobenzene, that decayed in a simulated natural water environment with box model (a) the control results under condition 1 (b) the control results under condition

\begin{tabular}{|c|c|}
\hline \multicolumn{2}{|c|}{$\begin{array}{c}\text { TABLE-2 } \\
\text { BOX MODEL ABOUT INTEGRATED } \\
\text { ATTENUATION OF NITROBENZENE IN A } \\
\text { SIMULATED NATURAL WATER ENVIRONMENT }\end{array}$} \\
\hline $\begin{array}{l}\text { Experimental } \\
\text { conditions }\end{array}$ & $\begin{array}{c}\text { Box model about integrated attenuation of } \\
\text { nitrobenzene in a simulated natural water } \\
\text { environment }\end{array}$ \\
\hline Condition 1 & $\begin{array}{l}C_{w}=0.2 \times \exp (-0.1948 t) /(1-0.5925 \times(1-\exp (- \\
0.1948 t)) \times(1-\exp (-0.2241 t)))\end{array}$ \\
\hline Condition 2 & $\begin{array}{l}\mathrm{C}_{\mathrm{w}}=\exp (-0.1981 \mathrm{t}) /(1-0.5873 \times(1-\exp (- \\
0.1981 \mathrm{t})) \times(1-\exp (-0.3953 \mathrm{t})))\end{array}$ \\
\hline
\end{tabular}

According to Fig. 8, under the two conditions, there were little differences between fitness and actual values of nitrobenzene in a simulated natural water environment when they decayed within $6 \mathrm{~h}$ and their concentrations were much higher than the model fitness in $24 \mathrm{~h}$ (in condition 2 was more obvious). After $6 \mathrm{~h}$, the adsorption/desorption got balanced and the degradation and volatilization processes of nitrobenzene in the solution were very slow. The nitrobenzene reduced extraordinary small, but the fitness of this model was far less than the actual values.

\section{Conclusion}

Under condition 1 and condition 2, we studied all aspects of natural attenuation of nitrobenzene in natural water environments. From the fitness rate constant of nitrobenzene, it can be known that the major fate of nitrobenzene in a simulated natural water environment was the adsorption of sediments.
In contrast to adsorption, photodegradation played a predominant role in the degradation process of nitrobenzene, followed by evaporation and desorption. The biodegradation process was relatively slower than other decay processes and it was not very predominant. In contrast to adsorption, volatilization, degradation and desorption processes also played significant roles in natural attenuation of nitrobenzene. Whether under condition 1 or 2 , the box model can reflect the natural attenuation process of nitrobenzene in a simulated natural water environment perfectly before the adsorption/desorption of nitrobenzene balanced. Since condition 1 and condition 2 had obvious representativeness to reflect the natural hydraulic conditions in natural water environments, we can predict that the box model can reflect the medium and high concentration of nitrobenzene perfectly before they balanced adsorption/ desorption in natural water environments. After nitrobenzene achieved balance between adsorption and desorption, the box model can not accurately reflect the natural attenuation of nitrobenzene in a simulated natural water environment.

\section{ACKNOWLEDGEMENTS}

The authors thank the Natural Science Foundation of Changchun Normal University for financial support.

\section{REFERENCES}

1. S.G. Pavlostathis and M.T. Prytula, Environ. Sci. Technol., 34, 4001 (2000).

2. D. Okutman Tas and S.G. Pavlostathis, Environ. Sci. Technol., 39, 8264 (2005).

3. A. Krause, W.G. Hancock, R.D. Minard, A.J. Freyer, R.C. Honeycutt, H.M. LeBaron, D.L. Paulson, S. Y. Liu and J.M. Bollag, J. Agric. Food Chem., 33, 584 (1985).

4. S. Susarla, Y. Yonezawa and S. Masunaga, Environ. Technol., 18, 75 (1997).

5. W.B. Neely, Chemical in the Environment. Marcel Dekker Inc. New York and Bassel (1980).

6. B. Quemerais, C. Lemieux and K.R. Lum, Chemosphere, 28, 1943 (1994).

7. C.M. Ye, Y.M. Xie, R.X. Ma and X.Y. Du, Environ. Sci., 6, 234 (1994).

8. P.S. Liss and P.G. Slater, Nature, 241, 181 (1974).

9. D. Mackay, S. Paterson and W.H. Schroeder, Environ. Sci. Technol., 20, 810 (1986).

10. H. Wang,C.M. Ye and Z.F. Lei, Environ. Sci., 13, 229 (1994).

11. Y.H. Zhao, P.Z. Lang and F.S. Long, Environ. Sci., 11, 53 (1991).

12. X. Quan, D.M. Xue, Y.Z. Zhao, F.1. Yang and C.D. Piao, Mar. Environ. Sci., 16, 10 (1997).

13. L. Hou, H.Y. Zhao, P.Z. Lang, Z.X. Lang and G.Z. Zhang, J. Northeast Normal Univ. (Nat. Sci. Ed.), 2, 48 (1999). 